\title{
Use-Dependent Growth of Pyramidal Neurons after Neocortical Damage
}

\author{
Theresa A. Jones and Timothy Schallert \\ Department of Psychology and Institute for Neuroscience, University of Texas at Austin, Austin, Texas 78712
}

\begin{abstract}
Unilateral damage to the forelimb representation area of the sensorimotor cortex in adult rats increases dendritic arborization of layer $\mathbf{V}$ pyramidal neurons of the contralateral homotopic cortex. Arbor size was maximum at approximately $18 \mathrm{~d}$ postlesion, following which there was a partial elimination, or pruning, of dendritic processes. These neural changes were closely associated with behavioral events. The overgrowth of dendrites was related in time to disuse of the contralateral (to the lesion) forelimb and over-reliance on the ipsilateral forelimb for postural and exploratory movements. The pruning of dendrites was related to a return to more symmetrical use of the forelimbs. To investigate the possibility that lesion-induced asymmetries in motor behavior contributed to dendritic arborization changes, movements of the forelimb ipsilateral to the lesion were restricted during the period of dendritic overgrowth through the use of one-holed vests. This interfered with the increase in dendritic arborization. In contrast, animals that were allowed to use both forelimbs, or only the forelimb ipsilateral to the lesion, showed the expected increases. When sham-operated rats were forced to use only one forelimb, no significant increases in arborization were found. Therefore, neither a lesion nor asymmetrical limb use alone could account for the dendritic overgrowth-it depended on a lesion-behavior interaction. Furthermore, greater sensorimotor impairments were found when the dendritic growth was blocked, suggesting that the neural growth and/or associated limb-use behavior were related to functional recovery from the cortical damage. Finally, in a second experiment, immobilization of the impaired limb during the pruning period did not prevent the elimination of processes. Thus, the pruning of neural processes was not related simply to the recovery of more symmetrical forelimb use. There may be a period early after brain damage during which marked neural structural changes can occur in the presence of adequate behavioral demand.

[Key words: dendritic branching, recovery of function, motor cortex, plasticity, forelimb preference, Golgi-Cox, pyramidal neurons]
\end{abstract}

\footnotetext{
Received Apr. 6, 1993; revised Sept. 10, 1993; accepted Sept. 29, 1993.

This work was supported by Grants NS 23964 and MH 18837. We thank Dorothy Kozlowski for helpful suggestions, Deborah James for perfusions and slide coding, and Donita Crippens, Lorna Hamamcy, Mark Tucker, Robin Edelman, and Margaret Beam for their assistance in the behavioral tests and surgeries.

Correspondence should be addressed to T. A. Jones, Beckman Institute, 405 N. Mathews, University of Illinois, Urbana, IL 61801.

Copyright (C) 1994 Society for Neuroscience $0270-6474 / 94 / 142140-13 \$ 05.00 / 0$
}

Unilateral lesions of sensorimotor cortical regions can lead to a reliance on the nonimpaired side of the body to compensate for lesion-induced contralateral impairments (Castro, 1977; Faugier-Grimaud et al., 1978; Passingham et al., 1983). Following unilateral damage to the forelimb representation area of the rat somatic-sensorimotor cortex, animals preferentially use the ipsilateral forelimb for reaching (Peterson and Francarol, 1938; Whishaw et al., 1986, 1991), forelimb placing (Barth, 1986; Barth et al., 1990; see also De Ryck et al., 1992), and postural support and movement (Jones and Schallert, 1992a). Neocortical damage in developing and adult animals can also lead to an increase in the dendritic arbors of neurons within nondamaged regions of the cortex (Kolb and Whishaw, 1989; Kolb and Gibb, 1991). Recently, we have found that unilateral lesions aimed at the forelimb representation area of the adult rat sensorimotor cortex (SMC-X) increase dendritic arborization of layer $\mathrm{V}$ pyramidal neurons of the contralateral motor cortex (Jones and Schallert, 1992a). This increase, primarily in higher-order branches, was largest in cortical tissue examined $18 \mathrm{~d}$ after the lesion, following which there was a reduction in dendritic arbors, but not a complete return to levels found in intact animals. In addition, the time course of the postlesion neuromorphological changes corresponded to a sequence of changes in the use of the forelimbs. Rats preferentially used the forelimb ipsilateral to the lesion for postural support during movement, such as rearing and other exploratory movements around vertical and horizontal surfaces of the home cage. The greatest severity of asymmetrical forelimb use preceded increased dendritic arborization. A subsequent return to more symmetrical limb use was roughly associated in time with the dendritic pruning seen $30-120 \mathrm{~d}$ postlesion.

It is well documented that changes in the experiences of intact adult animals can lead to neuromorphological changes in the CNS. For example, extensive exposure to motor learning tasks has been found to result in enhanced dendritic arborization and increased synapse numbers in areas of the cerebral and cerebellar cortex (Greenough et al., 1985; Withers and Greenough, 1989; Black ct al., 1990). Thus, it seems possible that the lesioninduced behavioral changes may contribute to postlesion changes in neural structure. The purpose of the present study was to examine whether the lesion-induced behavioral asymmetries caused by unilateral lesions of the forelimb sensorimotor cortex are directly related to the neural morphological changes that occur in the cortex contralateral to the lesion.

Characteristics of the basilar dendritic arborization of pyramidal neurons in layer $\mathrm{V}$ of the forelimb representation area of the sensorimotor cortex were measured following unilateral lesions to the homotopic cortex or sham operations of the opposite 

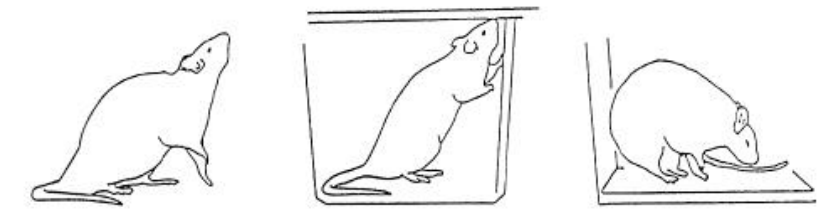

Figure 1. Observations were made of asymmetry in the use of the forelimbs for postural-support behaviors involved in movement including the use of a single forelimb to push off the floor during rearing (left), for support at the wall (center), and to land on when descending from a rear or from the wall (right). Animals with unilateral forelimb sensorimotor cortex lesions (SMC-X) preferentially use the forelimb ipsilateral to the lesion for these behaviors.

hemisphere. Restriction of the forelimb ipsilateral or contralateral to the lesion during the period of dendritic overgrowth was achieved by placing animals in plaster of paris casts resembling one-holed vests. As a control, rats were placed in twoholed vests that allowed unlimited movement of either limb. Of primary interest was whether restriction of the ipsilateral (nonimpaired) forelimb would block postlesion dendritic arborization increases. To address whether overuse of one forelimb alone was capable of producing measurable increases in basilar dendritic arbors in the contralateral cortex, a group of sham-operated rats also were fitted with casts to force use of only one forelimb. In an additional experiment, one-holed casts were used during the pruning period to extend the disuse of the impaired limb and test the possibility that the elimination of dendritic processes was related to the recovery of more normal use of both forelimbs.

This report was extensively discussed in an invited review article for The Journal of Neurotransplantation and Plasticity, Vol 4, 1993.

\section{Materials and Methods}

\section{Experiment 1}

\section{Subjects and surgery}

Fifty-five Long-Evans hooded male rats 4.5-7 months of age were used. Rats were individually housed in Plexiglas cages with wire mesh bottoms. Food and water were available ad libitum and rats were maintained on a 12:12 hr light/dark cycle. Animals were made tame by daily handling prior to surgery.

Electrolytic lesions were aimed at the caudal forelimb representation area (Neafsey et al., 1986) at coordinates corresponding to the overlapping somatic-sensory and motor representation of the forelimb (Hall and Lindholm, 1974; Wise and Donoghue, 1986). Animals were anesthetized with Equithesin $(25 \mathrm{mg} / \mathrm{kg}$ pentobarbital and $150 \mathrm{mg} / \mathrm{kg}$ chloral hydrate). Atropine methyl nitrate $(0.1 \mathrm{mg} / \mathrm{kg})$ was also administered to deter congestion and respiratory depression. The skull and dura were removed between 3.0 and $4.5 \mathrm{~mm}$ lateral to midline and between 0.5 $\mathrm{mm}$ posterior and $1.5 \mathrm{~mm}$ anterior to bregma. An uninsulated platinum electrode was lowered $1.7 \mathrm{~mm}$ below dura and anodal current $(1 \mathrm{~mA})$ was delivered for $120 \mathrm{sec}$ as the electrode was moved in eight equally spaced horizontal traverses through the exposed cortex. For sham-operated animals, all surgical procedures were performed up to, but not including, removal of the skull. In previous examinations of Nisslstained coronal sections using cytoarchitectonics to identify sensorimotor cortical regions (Jones and Schallert, 1989, 1992b; Barth et al., 1990), lesions centered at these coordinates have been found to produce complete or near complete damage to the overlapping somatic-sensory and motor representation area of the forelimb as well as considerable damage to nonoverlapping SI and MI forelimb representational areas.

\section{Forelimb immobilization procedure}

Rats were randomly assigned to the following groups: (1) SMC-X rats with ipsilateral limb immobilization (lesion + ipsi cast, $n=10$ ), (2)
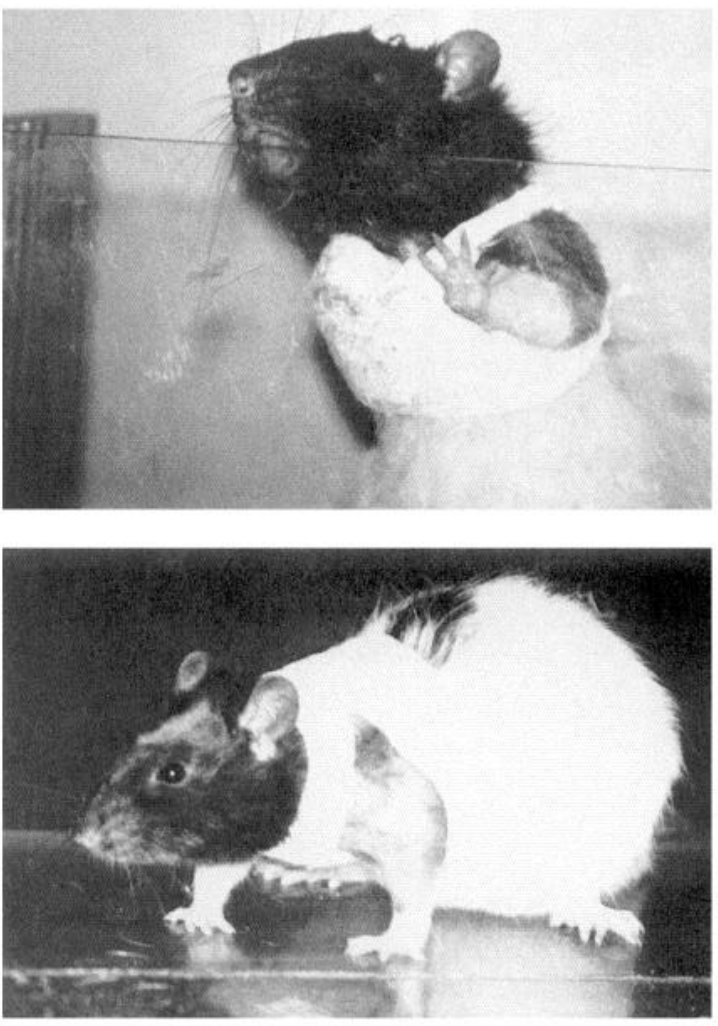

Figure 2. SMC-X and sham animals were prevented from using one forelimb for postural support through the use of one-holed vests formed out of plaster of paris (top). As a control, additional rats were placed in two-holed vests that permitted unrestricted movement of both forelimbs (bottom).

SMC-X rats with contralateral limb immobilization (lesion + contra cast, $n=10$ ), (3) SMC-X without immobilization (lesion-no cast, $n=$ 15), (4) sham with unilateral limb immobilization (sham + cast, $n=$ 10 ), and (5) sham without immobilization (sham-no cast, $n=9$ ). The forelimb was immobilized using light-weight plaster of paris cast material lined with felt (Fig. 2). Immediately following surgery and while anesthetized, one forelimb was placed in a retracted position against the chest and casts resembling one-holed vests were formed around the upper torso and the limb. A pocket of space was left around the casted forelimb to allow some limited movement. This form of cast was chosen (after rejection of other designs) because rats are typically unable to remove them although they can be easily removed by the experimenter without the use of anesthetics. In the lesion $(n=8)$ and sham $(n=7)$ groups without limb immobilization, control casts (two-holed vests) were used that were formed around the torso but did not confine either limb. Because the one-holed casts interfered with grooming, primarily of the head area ipsilateral to the casted limb, all animals were swabbed with a damp pad and thoroughly brushed once or twice daily. The torso and limb beneath the cast were also stimulated daily with a roundedtip probe.

Casts were removed by the experimenter on day 15 after surgery. Occasionally, animals partially or completely removed the casts. When this occurred, the casts were gently slipped back into the correct position on the rats. However, two sham-operated rats and seven SMC-X animals persistently removed their casts within the first few days after surgery (SMC-X: $n=5$ ipsi-limb casts and $n=2$ contra-limb casts removed; not included in the $n \mathrm{~s}$ for the lesion + cast groups above). In at least five rats, the successful cast removal may have been due to incorrectly formed casts, those that allowed rather large openings at the neck and abdomen. However, reinforcement of the casts proved unsuccessful. (It may be that once rats learn that the casts are removable, especially soon after casting, they are more likely to continue removal attempts.) After careful analysis the data from these nine animals showed no apparent differences in behavioral or anatomical variables in com- 
parison to data from like-operated rats with control casts. Therefore, these rats were added to the control-casted groups.

\section{Behavioral measures}

Limb-use asymmetry. Asymmetry in forelimb use was measured before surgery and on postlesion days $2,4,7,14,15$, and 17 . All filming was performed under red light during the dark cycle. Animals were filmed for $10 \mathrm{~min}$ within their home cage, following which they were filmed for $4 \mathrm{~min}$ on a three-walled platform (walls: 15,55 , and $15 \mathrm{~cm}$ length by $21 \mathrm{~cm}$ high with the $55 \mathrm{~cm}$ wall facing the camera). Instances of asymmetrical forelimb use were recorded from slow-motion playbacks, including observations of the forelimb used for support against the walls of the cage, the limb used to push off from the floor prior to rearing, and the limb on which an animal "landed" when descending from a rear or from the wall (Fig. 1). These behaviors are very frequently observed and easily quantified and appear to represent important motor behaviors displayed by the rats whenever they are active. An asymmetrical rear was defined as one forelimb being removed from the floor prior to the other forelimb (used to "push off') as the animal is moving into an upright position with the snout oriented upward. Asymmetrical limb use at the wall was considered to be any instance of support with one forelimb when the other forepaw was not in physical contact with the wall. The forelimb used to land was the forelimb that first made contact with the floor. For casted animals, the forelimb used was always the noncasted forelimb. Data were not collected while animals were engaged in eating, drinking, or grooming activity. A maximum of 35 observations were recorded from each session. These data are reported as the percentage of ipsilateral forelimb use [ipsi use/(ipsi + contra use) $\times$ 100]. Data from the platform and home cagc werc found to be very similar within animals and were pooled for the asymmetry variables (c.g., lesion-no cast, mean $\pm \mathrm{SE} \%$ ipsi limb use in the home cage $=$ $63.45 \pm 1.83$ and on the platform $=65.01 \pm 1.58$, pooled over postlesion days).

Estimates of forelimb activity per minute were computed as total number of observations/observation time. These activity data were variable for individual days of observation and therefore were pooled over days of casting (days 2-14) and postcasting (days 15 and 17). Although animals were not found to be more active on the platform than in the home cage, only home cage data were used for measurements of forelimb activity per minute (e.g., activity/min lesion-no cast in the home cage $=9.97 \pm 1.22$, on the platform $=10.93 \pm 0.69$; sham-no cast in the home cage $=14.43 \pm 1.67$, on the platform $=10.70 \pm 0.86$ ). It is important to note that the activity measurement fails to takc into account the number of times an animal uses both limbs simultaneously for postural support.

Tests of functional recovery. Measurements of sensorimotor function were made prior to surgery and on day 16 . The footfault test was used to measure coordinated forelimb placement during movement around a grid floor (described in detail in Barth et al., 1990). Rats were placed on an elevated grid $\left(24 \mathrm{~L} \times 29 \mathrm{~W} \times 30 \mathrm{H} \mathrm{cm}\right.$ with $2.5 \mathrm{~cm}^{2}$ grid openings) and allowed to roam for $2 \mathrm{~min}$. Rats traverse the grid by placing their limbs on the bars of the grid as they move. Following unilateral sensorimotor cortex lesions, the forelimb opposite the lesion is frequently incorrectly placed and slips through the grid openings (Colle et al., 1986; Barth et al., 1990). The number of falls (or misses) through the grid openings made by the contralateral and ipsilateral forelimbs, as well as the number of forelimb steps, was recorded. Forclimb footfault crrors for the contralateral and ipsilateral forelimb were computed as the percentage of misses per forelimb step.

Asymmetries in vibrissae-stimulated forelimb placing were measured using the placing and extinction placing tests (Barth, 1986; Jones and Schallert, 1992b). For the placing test, animals are held with the forelimbs hanging freely and the vibrissae are lightly stimulated with the edge of a counter top. In animals with sensorimotor cortex lesions, a lack of response may result when the vibrissae contralateral to the lesion are moved toward the counter whereas intact rats typically quickly place the forepaw ipsilateral to the stimulated vibrissae on the counter edge. For the extinction placing test, as the rats are moved toward the counter top, light stimulation is simultaneously applied to the opposite vibrissae by the experimenter's forefinger. Ten contralateral and 10 ipsilateral placing and cxtinction placing reactions werc determined in balanced order. Placing errors for each forelimb were computed as the percentage of missed placements per trial. In addition, placing reactions were examined across the footfault and vibrissae-stimulated placing tests using summed standardized values to yield a relative impairment score (plac- ing impairment $=z$ missed placements on the footfault test $+z$ missed vibrissae-stimulated placements +1 ).

In addition to the placing tests, animals were also tested for responsiveness to forelimb somatic-sensory stimulation using the bilateral tactile stimulation test, described in detail elsewhere (Schallert et al., 1983, 1986; Schallert and Whishaw, 1984). Rats were removed from the home cage and adhesive-backed pieces of paper (Avery self-adhesive removable labels, $1 / 2$ inch diameter) were placed bilaterally on the radial aspect of the wrist of both forelimbs. Upon return to the home cage, rats use the mouth to contact and remove the stimuli one at a time. The latency and order (left vs right) of stimulus contact were recorded on four or five trials.

\section{Histological procedures}

Rats were anesthetized with a lethal dose of sodium pentobarbital and perfused intracardially with saline followed by light fixation perfusion ( $100 \mathrm{ml}$ over $2 \mathrm{~min}$ ) using a $10 \%$ formalin solution. Following extraction, wholc brains were quartered (along midline and through occipital cortex) and placed in Golgi-Cox solution for three weeks. Following standard reaction and dehydration procedures, brains were embedded in epoxy resin and $200 \mu \mathrm{m}$ coronal sections were cut throughout the rostral twothirds of the cerebrum. Slides containing sections from within the nondamaged sensorimotor cortex were coded by an independent researcher prior to quantification. Coronal sections of the damaged hemisphere were examined using a Bausch \& Lomb microprojector (20x magnification). The boundaries of the lesions, including adjacent necrotic areas, were drawn onto schematic representations of coronal sections adapted from Paxinos and Watson (1986).

\section{Selection and quantification of pyramidal neurons}

The basilar dendritic branches of 10-12 layer $\mathrm{V}$ pyramidal neurons were drawn $(450 \times)$ from the presumed forelimb motor representation area of the nondamaged cortex of animals in lesion groups and both hemispheres of sham operates. Pyramidal neurons were selected from two or three sections between bregma and $1.2 \mathrm{~mm}$ anterior to bregma. In a previous examination of the placement of the forelimb area in Nisslstained sections it was found that although there is variability in the rostral-caudal extent of the forelimb somatic-sensory and motor overlap area, this overlap could be found in slices between bregma and $1.2 \mathrm{~mm}$ anterior to bregma (Jones and Schallert, 1989). It is more difficult to specify precisely the extent of the forelimb overlap area using cytoarchitectonics in Golgi-stained sections, but by only using sections within these coordinates for quantification, in combination with available cytoarchitectural information, the chance of measuring forelimb area neurons is optimized. Neurons were selected in areas with large pyramidal cells in layer $\mathrm{V}$, presumably corresponding to the MI forelimb representation including that which overlaps with SI. Medial to lateral, pyramidal neurons were chosen from between the region just lateral to the medial agranular area, bordering the dorsal peak of the corpus callosum, and approximately $4.0 \mathrm{~mm}$ lateral to midline. Neurons were chosen using selection criteria similar to those described previously (Flood et al., 1987; Kolb and Gibb, 1991).

For each neuron, the number and centrifugal order of basilar dendritic branches were recorded. Using centrifugal ordering (Coleman and Riesen, 1968; Uylings et al., 1989), branch points were numbered beginning at the soma and moving outward so that a branch arising directly from the soma is assigned an order of 1 , a branch in this segment is assigned an order of 2, and so forth. Concentric circle analysis was used (Sholl, 1956) to assess the spatial extent of the basilar dendritic tree. A transparency with concentric circles at $20 \mu \mathrm{m}$ intervals (adjusted for magnification) was placed centering over the soma. The number of times each circle was intersected by dendritic processes was recorded.

\section{Statistical analyses}

Of primary interest in this experiment was whether (1) lesions produce changes in dendritic branch patterns, (2) blocking use of the ipsilateral limb interferes with or otherwise alters postlesion branching patterns, (3) limb immobilization per se in intact animals is sufficient to change dendritic branching, and (4) changes in branching patterns are produced by the casting procedure when the contralateral limb (impaired limb) is immobilized in SMC-X animals. Therefore, planned comparisons were performed on anatomical data using the following withinand between-group contrasts: (1) lesion-no cast versus sham-no cast, (2) lesion-no cast versus lesion + ipsi cast, (3) the hemisphere ipsilateral versus contralateral to the casted limb of sham-operated rats, and (4) 
lesion-no cast versus lesion + contra cast. All comparisons were performed using SAS general linear models procedure for contrasts. Dendritic branch data were analyzed for simple effects of groups and concentric circle data were analyzed for effects of group and for linear circle by group interaction effects. Data from left and right hemispheres of sham-no cast rats were not significantly different and were pooled. For behavioral measures the third contrast was substituted with a comparison of sham-no cast versus sham + cast animals. Limb-use measurements were analyzed using interaction contrasts for group by condition over time (pretest, casted days $2-14$, or postcast days 15 and 17). Data from sensorimotor tests were analyzed using contrasts for simple effects of groups. Additional post hoc comparisons were performed when appropriate using the Tukey HSD test.

\section{Experiment 2}

In our previous study (Jones and Schallert, 1992a) it was found that after an $18 \mathrm{~d}$ period of dendritic overgrowth, a partial reduction in dendritic arborization occurred. This pruning may be part of the recovery process, perhaps reflective of a selective maintenance of some synapses. However, other explanations remain possible. For example, the period of pruning was associated with more symmetrical use of the forelimbs and it seemed possible that the reduction in arborization simply reflected a return to more normal levels of use in the ipsilateral forelimb. Therefore, a second experiment was designed to assess whether arbor size could be maintained at high levels by forcing animals to use only the ipsilateral forelimb during the normal pruning period. Fiftyfour male Long-Evans rats between five and six months of age were used. Surgical, anatomical, and behavioral procedures were performed as in experiment 1.

Twenty days after surgery, lesion or sham-operated rats were anesthetized with Equithesin and placed in immobilizing or control casts, matching the five conditions used in experiment 1: lesion-no cast $(n=$ $12)$, lesion + contra cast $(n=10)$, lesion + ipsi cast $(n=9)$, sham-no cast $(n=12)$, and sham + cast $(n=10)$. It became apparent in early work on this experiment that some animals, most notably SMC-X rats with the ipsilateral limb immobilized, were more successful than typical at removing the casts, most commonly within the first day after casting ( $n=6$ lesion + ipsi cast rats and $n=3$ sham + cast). An interesting possibility is that postlesion compensatory use of the ipsilateral forelimb causes rats to be more adcpt at removing casts when this limb is restricted. This was remedied in subsequently casted animals by very loosely suturing the hide of the upper back with the cast (before hardening) with a single connection. One rat was excluded from this study because it removed its cast in the second week after limb immobilization. The animals that removed their casts within the first few days after limb immobilization were added to the control-casted groups because they showed very similar anatomical results, behavioral test results, and limb-use behavior, with the exception of limb activity. SMC-X animals that were subsequently found to have removed their ipsilaterallimb casts had been more active with their ipsilateral forelimb and contralateral forelimb prior to the casting procedure (activity/min: ipsi limb $=19.29 \pm 2.50$, contra $\operatorname{limb}=8.13 \pm 1.18$, vs lesion + control casts: $12.53 \pm 1.71$ and $5.98 \pm 0.92$, respectively). (The omission of these animals from the lcsion + ipsi cast group should not bc considercd as biasing this group because the cast-removal problem was remedied in additional animals.) The two sham-operated animals that removed their one-holed casts did not show more limb-use activity than other sham animals (mean precast limb-use activity/min per limb $=7.48 \pm$ 2.09 vs $8.18 \pm 0.85$, respectively).

Casts were removed on day 35 postlesion. Behavioral tests were administered prior to surgery and on days 19 and 36 . Limb-use asymmetries were recorded before limb immobilization on postlesion days $2,4,7,14$, and 18 , after limb immobilization on postlesion days 22 , 24,27 , and 34 , and after cast removal on days 35 and 37 . Rats were killed on day 38. Statistical analyses were performed as in experiment 1.

\section{Results}

\section{Experiment 1: early forelimb restriction}

\section{Lesion verification}

All animals included in this study had lesions that appeared to result in complete or near complete damage to the region corresponding to the overlapping sensory and motor representation area of the forelimb as well as considerable damage to nonov-

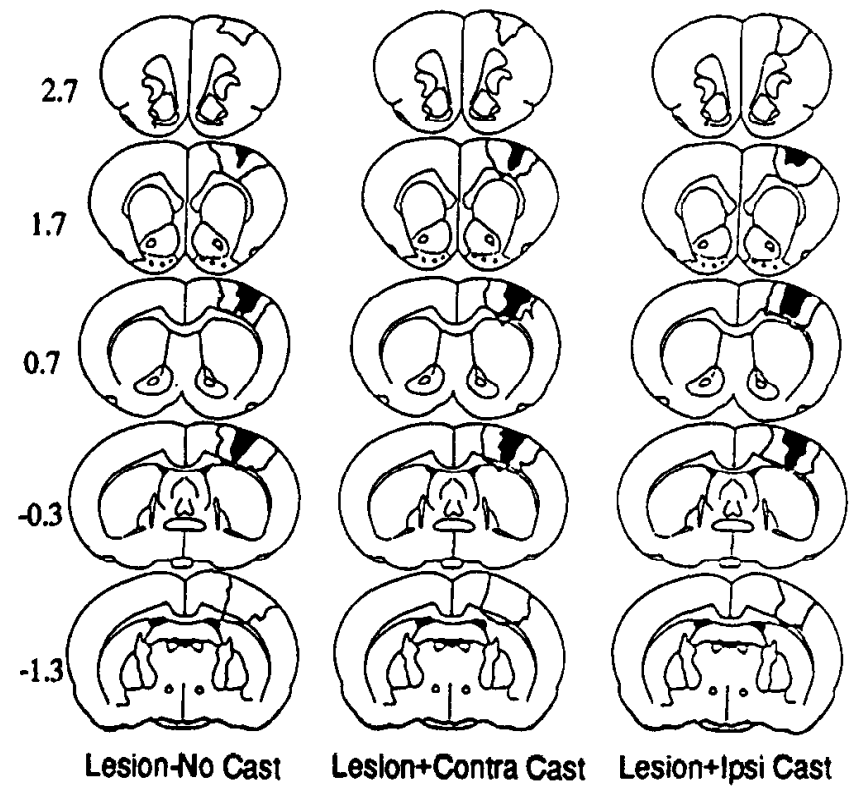

Figure 3. Coronal representations of the area damaged by all lesions (black) and the outer boundary of the damage (solid lines) for SMC-X animals examined at $18 \mathrm{~d}$ postlesion. Numbers adjacent to coronal sections represent coordinates in millimeters relative to bregma.

erlapping forelimb representation areas. As shown in Figure 3, although there was a typical variability across medial to lateral and dorsal to ventral extent, no major differences in the extent or placement of the lesions could be found between groups of animals. Judging by coordinates, it is likely that most lesions produced slight damage to the anterior and lateral portion of the hindlimb representation area. Most lesions produced at least superficial damage to the underlying corpus callosum and at least two animals in each group had lesions that penetrated the corpus callosum to produce superficial damage to the underlying striatum. No differences in the measured behavioral or anatomical data could be traced to apparent differences in lesion placcment.

\section{Basilar dendritic arborization}

Dendritic branching. Unilateral forelimb area lesions resulted in an increase in the number of basilar dendritic branches of layer $\mathrm{V}$ pyramidal neurons of the contralateral homotopic cortex (Fig. $4 A$ ), which was expected based on data from a previous experiment (Jones and Schallert, 1992a). Lesion-no cast animals had a mean $\pm S E$ of $25.01 \pm 0.97$ branches per neuron whereas sham-no cast rats had $20.29 \pm 0.55$. As in the previous experiment, the greatest increase in branches occurred in higher level (relative to the soma) branches (Fig. 4B). A significant effect was found for total branch number per neuron $[F(1,49)=19.39$, $p<0.0001]$ and for level 2 and higher-order branches $[F \mathrm{~s}(1,49)$ $=6.78-19.43$, $p$ s $<0.02]$.

Following the lesions, immobilization of the ipsilateral (nonimpaired) forelimb resulted in a significant reduction in the total number of basilar dendritic branches relative to lesion-no cast rats $[F(1,49)=5.75, p<0.05]$. Significant reductions were found in fourth $(F=5.70, p<0.05)$ and fifth and higher $(F=8.60$, $p<0.01$ ) order branches only (Fig. $4 B$ ). The lesion + ipsi cast group was not significantly different from sham $(p>0.05$, Tukey HSD).

In contrast, immobilization of the impaired (contralateral) 
A

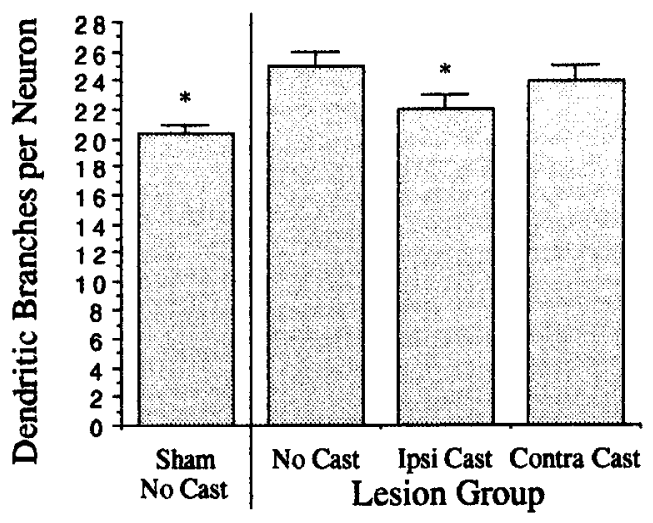

B

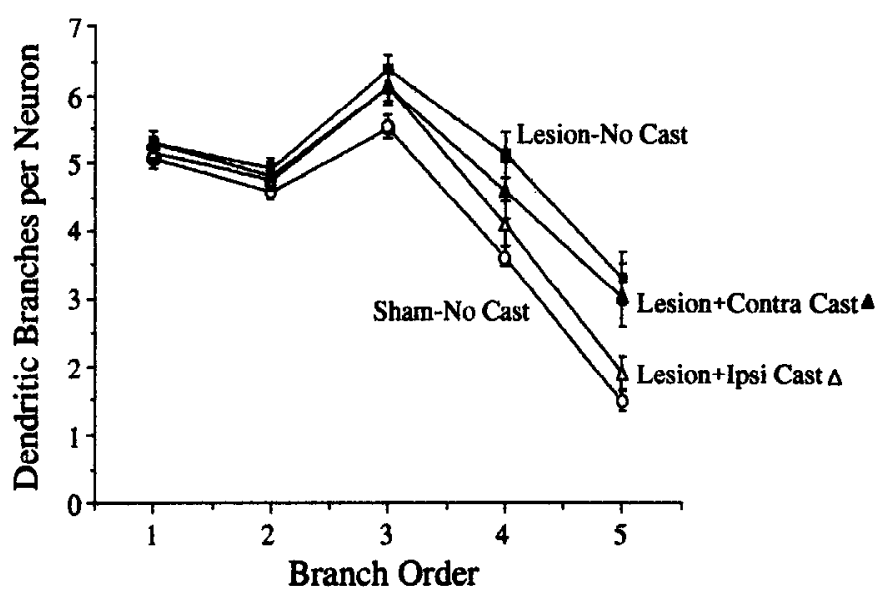

Figure 4. Basilar dendritic arborization of layer V pyramidal neurons in the forelimb motor representation cortex opposite unilateral forelimb sensorimotor cortex lesions. SMC-X animals that were allowed to use both forelimbs (Lesion-No Cast) or only the ipsilateral forelimb (Lesion + Contra cast) showed an increase in the total number of basilar dendritic branches $(A)$ in comparison to sham animals (Sham-No Cast). This increase was greatest at higher-order branch levels $(B)$. Immobilization of the forelimb ipsilateral to the lesion (Lesion + Ipsi Cast) caused a reduction in the number of dendritic branches in comparison to Lesion-No cast animals $(A)$, especially in higher-order branches $(B)$. Data are shown as means $\pm \mathrm{SE} .{ }^{*}, p<0.05$ significantly different from Lesion-No Cast on planned comparisons.

forelimb did not significantly affect dendritic branching. The total number of dendritic branches per neuron in lesion + contra cast rats was slightly reduced but not significantly different from lesion-no cast $[F(1,49)=0.83, p>0.05]$. The lesion + contra cast group was also significantly different from sham-no cast ( $p$ $<0.05$, Tukey HSD).

As shown in Figure 5, immobilization of one forelimb in sham-operated rats did not result in an increase in branches in the hemisphere opposite the "forced-use" forelimb. Significant differences between hemispheres were not found for either the total number of basilar dendritic branches per neuron $[F(1,49)$ $=0.18, p>0.05]$ or the branch number at any given level $[F \mathrm{~s}(1,49)=0.02-0.47, p \mathrm{~s}>0.05]$.

Concentric circle results. Relative to sham-operated animals, pyramidal neurons of lesion-no cast animals showed increases in arborization, as measured by circle intersections, at $20 \mu \mathrm{m}$ from the soma center, maximum increases at $40 \mu \mathrm{m}$, and a progressive decline in intersections with increasing distance from the soma (Table 1). Planned comparisons resulted in a significant effect for group [lesion-vs sham-no cast, $F(1,49)=19.39$, $p<0.0001]$ and circle by group interaction including the first 10 circles $[F(1,490)=34.56, p<0.0001]$. The number of circle intersections was significantly greater in lesion-no cast animals for the first five circles, or $100 \mu \mathrm{m}$ ( $p$ s $<0.05$, Tukey HSD).

As with dendritic branching, immobilization of the ipsilateral forelimb in SMC-X animals resulted in a decreased number of circle intersections in comparison to lesion-no cast. This effect was greatest for the area closest to the soma. Planned comparisons resulted in a significant effect for group (lesion + ipsi cast vs lesion-no cast) $[F(1,49)=5.75, p<0.05]$ and a significant circle by group interaction effect $[F(1,490)=14.17, p<0.0002]$. Circle intersections were significantly reduced in lesion + ipsi cast rats for the first three circles or $60 \mu \mathrm{m}$ ( $p \mathrm{~s}<0.05$, Tukey HSD).

Similar to the results of branch analysis, SMC-X rats with the contra limb casted showed circle intersection numbers that were similar, but slightly (nonsignificantly) reduced, in comparison to lesion-no cast. Likewise, no significant interhemispheric or interaction effects were found for sham + cast animals.

\section{Forelimb use in postural support behaviors}

Limb-use asymmetry. Following the lesions, there was an increase in the use of the ipsilateral forelimb relative to the contralateral forelimb (Fig. 6). The percentage of ipsilateral forelimb use was increased significantly in comparison to shams [lesionvs sham-no cast group: $F(1,49)=11.44, p<0.002$ ]. Preferential use of the ipsilateral forelimb in lesion-no cast rats was found for each of the measured limb-use behaviors (rears, support at a wall, and lands). Pooled over postlesion days, lesion-no cast animals uscd the ipsi forclimb alone for $66.10 \pm 2.25 \%$ of movements at the wall, $62.96 \pm 2.14 \%$ of rears, and $59.31 \pm$ $2.32 \%$ of landings when descending from an upright position.

Of interest was the degree to which animals were capable of using their previously immobilized limb for postural support after their casts were removed. Examples of use of the previously casted limb for postural support, as well as for grooming and eating behaviors, could typically be seen immediately upon returning the animals to the home cage following cast removal. The measured postural support behaviors were, however, not very frequent at this time because animals invariably began a prolonged bout of grooming. At the time of day 15 filming (4$6 \mathrm{hr}$ after cast removal), lesion + cast and sham + cast animals showed limb-use asymmetries that shifted toward the lesion or sham-no cast groups, respectively, but which were also reflective of their former casted states (Fig. 6). That is, rats showed greater disuse of the formerly casted forelimb in comparison to control/ no-casted rats. Following cast removal, the percentage of ipsilateral use in lesion + ipsi cast rats was similar to that of the sham-no cast group. Group by condition planned comparisons for postcast days resulted in a significant effect between sham + cast versus sham-no cast $[F(1,139)=7.61, p<0.01]$, between lesion-no cast and sham-no cast $[F(1,139)=10.77, p<0.002]$, between lesion-no cast and lesion + ipsi cast rats $[F(1,139)=$ $10.41, p<0.002]$, and between lesion-no cast and lesion + contra cast rats $[F(1,139)=11.09, p<0.002]$.

Limb-use activity. As shown in Table 2, the asymmetry in the 


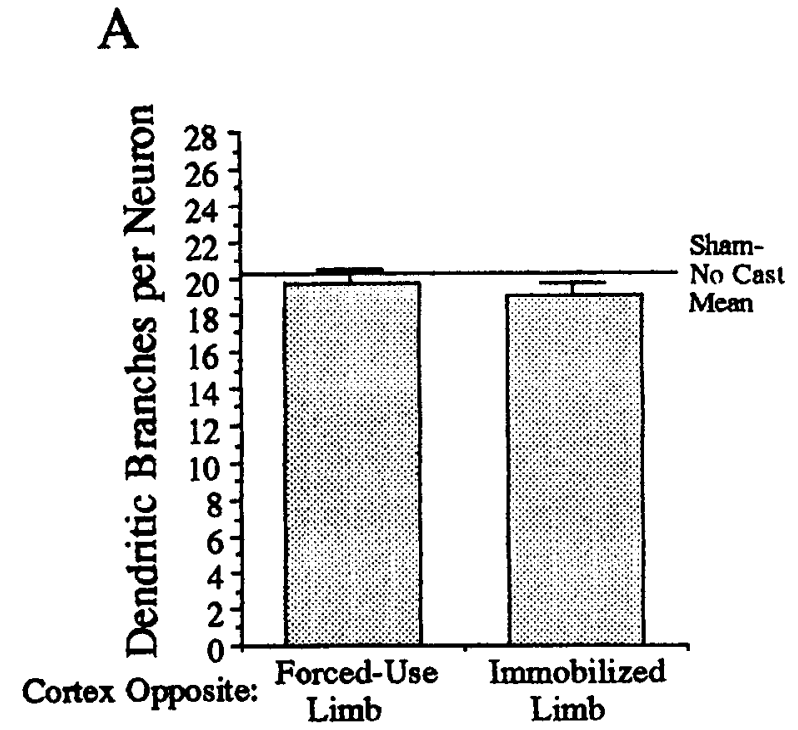

B

Figure 5. Mean \pm SE basilar dendritic branching in the sham + cast rats, shown relative to the immobilized forelimb and the forced-use forelimb. Immobilization of one forelimb in sham animals did not significantly alter the total number $(A)$ or pattern $(B)$ of dendritic branching.

use of the forelimbs for postural support behaviors in lesionno cast animals was primarily due to disuse of the contralateral (impaired) limb rather than increased use of the ipsilateral limb. The number of observations per minute of contralateral limb use in lesion-no cast rats was significantly reduced in comparison to sham-no cast rats between two and $14 \mathrm{~d}$ postlesion ["casted" days: $F(1,139)=5.23, p<0.05]$ but ipsilateral limb activity was not significantly affected by the lesion.

The activity of the forced-use limb of lesion + cast and sham + cast animals was not significantly affected during or after casting for any planned comparison. Following cast removal, the use of the ipsilateral limb in lesion + ipsi cast rats remained reduced in comparison to lesion-no cast [postcast: $F(1,139)=$
$4.58, p<0.05]$. Lesion + contra cast rats showed no significant differences in forelimb activity following cast removal in comparison to lesion-no cast. The control (two-holed) casts did not appear to reduce activity in comparison to animals without casts. SMC-X animals that had control casts showed a mean of $6.31 \pm 1.74$ ipsilateral and $3.82 \pm 1.03$ contralateral observed limb-use activity per min. This was similar to SMC-X animals that had removed their casts: $5.34 \pm 0.93$ ipsi and $2.55 \pm 0.47$ contra.

Of the types of limb-use behaviors, the most frequently recorded for sham- and lesion-no cast rats was activity at the wall. Animals were often observed to show a single rear, followed by several seconds of movement around the walls of the

Table 1. Basilar dendritic arborization following early forelimb restriction: intersections between circles and dendritic processes

\begin{tabular}{|c|c|c|c|c|c|c|c|}
\hline \multirow[b]{2}{*}{ Group } & \multicolumn{6}{|c|}{ Concentric circle distance $(\mu \mathrm{m})$} & \multirow{2}{*}{$\begin{array}{l}\text { Total } \\
\text { inter- } \\
\text { sections } \\
\text { (all } \\
\text { circles) }\end{array}$} \\
\hline & 20 & 40 & 60 & 80 & 100 & 120 & \\
\hline Sham-no cast & $\begin{array}{c}8.86^{*} \\
(0.16)\end{array}$ & $\begin{array}{l}11.42^{*} \\
(0.39)\end{array}$ & $\begin{array}{c}9.42^{*} \\
(0.37)\end{array}$ & $\begin{array}{r}6.41^{*} \\
(0.34)\end{array}$ & $\begin{array}{c}4.40^{*} \\
(0.29)\end{array}$ & $\begin{array}{c}2.82 \\
(0.25)\end{array}$ & $\begin{array}{l}46.96^{*} \\
(1.79)\end{array}$ \\
\hline Lesion-no cast & $\begin{array}{l}10.77 \\
(0.34)\end{array}$ & $\begin{array}{c}14.03 \\
(0.51)\end{array}$ & $\begin{array}{c}12.21 \\
(0.55)\end{array}$ & $\begin{array}{c}8.68 \\
(0.54)\end{array}$ & $\begin{array}{c}5.97 \\
(0.43)\end{array}$ & $\begin{array}{c}3.72 \\
(0.31)\end{array}$ & $\begin{array}{l}59.92 \\
(2.74)\end{array}$ \\
\hline Lesion + ipsi cast & $\begin{array}{c}9.44^{*} \\
(0.28)\end{array}$ & $\begin{array}{c}12.43^{*} \\
(0.52)\end{array}$ & $\begin{array}{c}9.77^{*} \\
(0.61)\end{array}$ & $\begin{array}{c}7.25 \\
(0.58)\end{array}$ & $\begin{array}{c}4.87 \\
(0.52)\end{array}$ & $\begin{array}{c}3.29 \\
(0.48)\end{array}$ & $\begin{array}{l}51.29^{*} \\
(3.44)\end{array}$ \\
\hline Lesion + contra cast & $\begin{array}{c}9.90 \\
(0.41)\end{array}$ & $\begin{array}{c}13.35 \\
(0.68)\end{array}$ & $\begin{array}{l}11.28 \\
(0.89)\end{array}$ & $\begin{array}{c}8.12 \\
(0.80)\end{array}$ & $\begin{array}{l}5.52 \\
(0.62)\end{array}$ & $\begin{array}{c}3.24 \\
(0.36)\end{array}$ & $\begin{array}{l}55.04 \\
(3.48)\end{array}$ \\
\hline $\begin{array}{l}\text { Sham + cast } \\
\text { Cortex opposite: }\end{array}$ & & & & & & & \\
\hline Force-use limb & $\begin{array}{c}9.14 \\
(0.31)\end{array}$ & $\begin{array}{l}11.56 \\
(0.46)\end{array}$ & $\begin{array}{c}9.09 \\
(0.75)\end{array}$ & $\begin{array}{c}6.17 \\
(0.83)\end{array}$ & $\begin{array}{c}4.08 \\
(0.79)\end{array}$ & $\begin{array}{c}2.67 \\
(0.69)\end{array}$ & $\begin{array}{c}45.94 \\
(4.66)\end{array}$ \\
\hline Immobilized limb & $\begin{array}{c}9.24 \\
(0.33)\end{array}$ & $\begin{array}{c}10.77 \\
(0.34)\end{array}$ & $\begin{array}{c}8.62 \\
(0.54)\end{array}$ & $\begin{array}{c}6.02 \\
(0.54)\end{array}$ & $\begin{array}{c}3.98 \\
(0.38)\end{array}$ & $\begin{array}{c}2.62 \\
(0.37)\end{array}$ & $\begin{array}{c}44.12 \\
(2.60)\end{array}$ \\
\hline
\end{tabular}

Data arc shown as mean \pm SE intersections per neuron per animal at distances relative to the soma center.

$* p<0.05$ significantly different from Lesion-no cast on planned comparisons. 


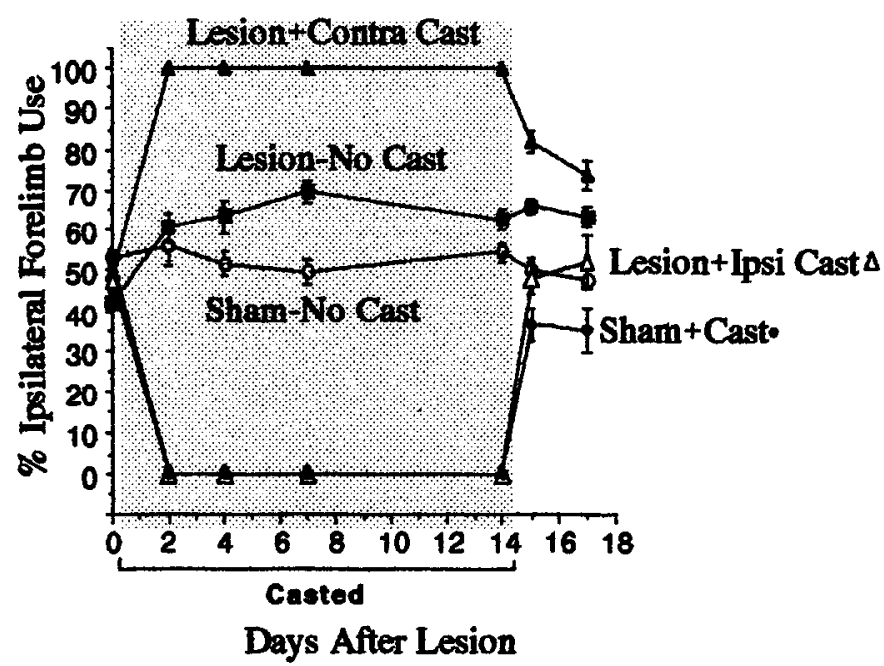

Figure 6. Asymmetry in the use of the forelimb for postural-support behaviors. The lesions resulted in preferential use of the ipsilateral to the lesion forelimb (Lesion-No Cast group). The use of the ipsilateral or contralateral forelimb was blocked between 1 and $15 \mathrm{~d}$ postlesion using immobilizing casts (Lesion + Ipsi and Lesion + Contra Cast). Following cast removal, all animals began immediately to use the formerly immobilized limb, but the postcast asymmetry of lesion and sham animals was reflective of their previous casted state. Forelimb use in Sham + Cast animals is shown relative to the immobilized limb (i.e., the casted limb is treated as the "ipsilateral" limb so that the \% ipsi is 0 during casting). Data are shown as means $\pm \mathrm{SE}$.

cage during which many occurrences of single-limb use were recorded. Rats with casts showed reduced activity at the wall relative to other limb-use behaviors. Lesion and sham animals with one-holed casts showed significantly reduced proportionate activity at the wall relative to the lesion- and sham-no cast animals, respectively ( $p$ s $<0.001$ ). This effect was largest in lesion + cast animals. During casting, the proportion of activity at the wall (wall observations/total observations) was $19.86 \pm$ $1.97 \%$ in lesion + ipsi cast, $24.49 \pm 2.48 \%$ in lesion + contra cast, and $30.56 \pm 2.55 \%$ in sham + cast. Lesion-no cast rats also showed a less major but significant proportionate reduction in activity at the wall in comparison to sham-no cast ["casted days," mean \pm SE proportion of wall activity lesion-no cast $=$

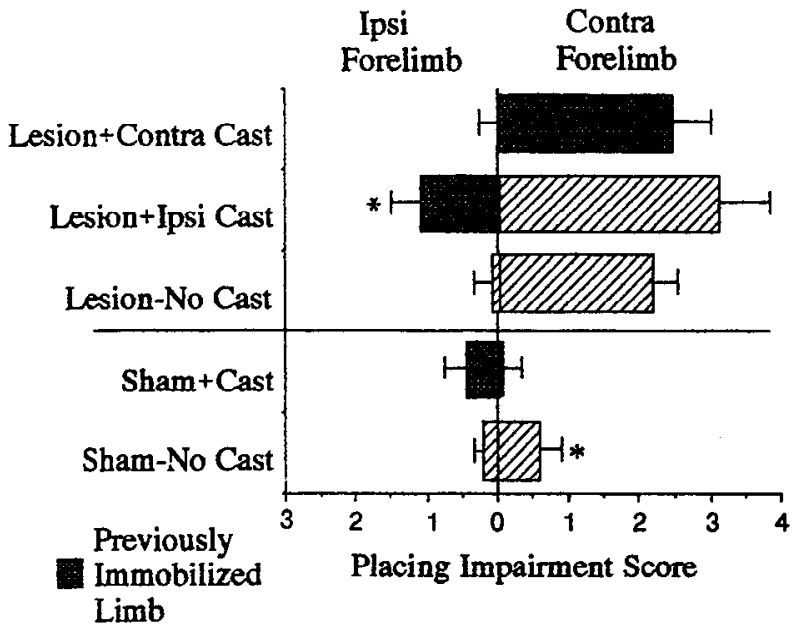

Figure 7. Relative placing impairment on day 16 after the lesion ( $1 \mathrm{~d}$ after cast removal). All lesion groups showed impairments in placing the contralateral forelimb. Lesion + Ipsi Cast rats also showed impaired placing of the ipsilateral forelimb in comparison to Lesion-No Cast animals. Placing of the forelimb contralateral to the lesion was not improved by forced use in the Lesion + Ipsi Cast group. Data are shown as mean \pm SE standardized values. ${ }^{*}, p<0.05$ significantly different from Lesion-No Cast on planned comparisons.

$39.73 \pm 1.71$ vs sham-no cast $=48.35 \pm 1.52, F(1,49)=6.73$, $p<0.01]$.

The reduction in activity at the wall in casted animals is interesting because, of the types of limb use, this is the only one for which lesion + ipsi cast rats showed a relatively consistent preference for use of the ipsilateral (to the lesion) forelimb following cast removal. Eight of the 10 lesion + ipsi cast rats showed an ipsilateral bias ( $>50 \%$ ipsilateral use, mean $\pm \mathrm{SE}=$ $64.01 \pm 3.70 \%$ ) at the wall and for every rat in this group this was the behavior for which the strongest ipsilateral limb use was expressed relative to other limb-use behaviors. In contrast, contralateral biases (i.e., preference for the forced-use/impaired limb) were seen for the other limb-use behaviors (mean \pm SE ipsi rears $=39.55 \pm 4.38 \%$, lands $=39.25 \pm 4.52 \%)$. Similarly, following cast removal, sham + cast animals showed a significantly increased preference for use of the forced-use limb in comparison to sham-no cast for all limb-use behaviors except activity at the wall. For example, sham + cast animals used the

\begin{tabular}{lllll}
\hline Table 2. Limb-use activity & & & \\
Group & Forelimb & Presurgery & Casted & Postcast \\
\hline Sham-no cast & Ipsi & $5.63 \pm 1.50$ & $7.47 \pm 1.18$ & $7.30 \pm 1.41$ \\
& Contra & $5.71 \pm 1.73$ & $6.60 \pm 1.00^{*}$ & $7.87 \pm 1.64$ \\
Lesion-no cast & Ipsi & $5.29 \pm 2.12$ & $5.81 \pm 0.97$ & $7.91 \pm 1.46$ \\
& Contra & $4.83 \pm 2.05$ & $3.17 \pm 0.56$ & $3.99 \pm 0.74$ \\
Lesion + ipsi cast & Ipsi & $5.06 \pm 1.95$ & $0.00 \pm 0.00$ & $2.97 \pm 0.65$ \\
& Contra & $4.61 \pm 1.71$ & $2.90 \pm 0.61^{*}$ & $5.43 \pm 1.78$ \\
Lesion + contra cast & Ipsi & $7.55 \pm 2.77$ & $2.72 \pm 0.79$ & $6.55 \pm 2.22$ \\
& Contra & $7.65 \pm 2.81$ & $0.00 \pm 0.00$ & $1.99 \pm 0.55$ \\
Sham + cast & & & & \\
Force-use limb & & $6.66 \pm 2.65$ & $8.76 \pm 1.98$ & $9.76 \pm 1.85$ \\
Immobilized limb & & $6.70 \pm 2.79$ & $0.00 \pm 0.00$ & $5.66 \pm 1.91$
\end{tabular}

Data are shown as the mean \pm SEM observations of asymmetrical forelimb use per min within the home cage ${ }^{*} p<0.05$ significantly different from Lesion-no cast on planned comparisons. 
formerly forced-use limb for $74.08 \pm 3.82 \%$ of the rears but for only $52.03 \pm 4.27 \%$ of wall activity. These data seem to indicate that the measured limb-use behaviors are sensitive to practice effects.

\section{Functional effects of limb immobilization}

Placing impairment. As shown in Figure 7, postlesion immobilization of the ipsilateral (nonimpaired) forelimb resulted in the greatest overall impairment on the placing tests. The impairment score for the ipsilateral forelimb of lesion + ipsi cast rats was significantly greater than lesion-no cast $[F(1,49)=9.40$, $p<0.005$ ]. Forced use of the contralateral (impaired) forelimb in the lesion + ipsi cast group failed to significantly change the performance of this limb relative to lesion-no cast $[F(1,49)=$ $0.06, p>0.05]$. In the lesion-no cast group, placing of the contralateral, but not ipsilateral, forelimb was significantly different from sham-no cast $[F(1,49)=6.67, p>0.02]$. Immobilization of the contralateral forelimb failed to have a significant effect in comparison to lesion-no cast $[F(1,48)=0.60, p$ $>0.05]$.

On the footfault test, lesion + ipsi cast rats showed the greatest number of missed placements with both the contralateral ( 34.55 $\pm 6.10 \%$ of steps missed) and ipsilateral $(19.23 \pm 3.33 \%)$ forelimb but these effects were not significant in comparison to the contra and ipsi forelimb of the lesion-no cast group (25.38 \pm $3.33 \%$ and $11.91 \pm 1.73 \%$, respectively). Footfault placing errors in the lesion-no cast group were also not significantly different from sham-no cast at this day postlesion $(19.01 \pm 3.28 \%$ and $16.09 \pm 1.65 \%$, "contra" and "ipsi" forelimb). The footfault scores of lesion + contra cast rats (contra: $22.92 \pm 2.67 \%$; ipsi: $12.99 \pm 2.67 \%$ ) were similar to those of lesion-no cast.

On the vibrissae-stimulated placing tests, lesion + ipsi cast rats showed the greatest number of missed placements with the ipsilateral forelimb (14.58 $\pm 4.94 \%$ of trials) and this was significantly increased relative to the lesion-no cast group, which showed few missed ipsilateral placements $[1.67 \pm 1.05 \% ; F(1,49)$ $=8.19, p<0.01]$. Contralateral forelimb placing was not significantly affected in either lesion + cast group (lesion + ipsi cast: $38.75 \pm 9.21 \%$; + contra cast: $41.00 \pm 11.08 \%)$ in comparison to lesion-no cast $(30.67 \pm 7.68 \%)$. However, the lesion + no cast group showed significantly more contralateral missed placements than sham-no cast $[1.11 \pm 1.11 \% ; F(1,49)=6.29$, $p<0.02]$. No significant effects were found between groups for any individual or combined test measure for presurgery (day 0 ) tests. Sham + cast rats showed slightly greater numbers of placing errors with the formerly casted limb but this group was not significantly different from sham-no cast on any measure.

Response to somatic-sensory stimulation. Consistent with the results of forelimb area lesion effects reported previously (Barth and Schallert, 1987; Barth et al., 1990; Jones and Schallert, 1992b), Lesion-no cast animals preferentially contacted tactile stimuli placed on the ipsilateral forelimb before contacting stimuli placed on the contralateral forelimb (data not shown). Lesion + ipsi cast animals showed a significantly slower latency to respond to stimuli placed on the ipsilateral, previously casted, limb. The latency to contact ipsilateral stimuli was $31.07 \pm$ $10.07 \mathrm{sec}$, which was significantly slower than lesion-no cast $(10.54 \pm 2.64 \mathrm{sec}, p<0.05)$. The latency to contact contralaterally placed stimuli was not significantly different between these groups (contact latency $=24.77 \pm 6.99$ vs $20.71 \pm 4.17$, respectively). Lesion + contra cast rats showed a slightly slower mean response time to stimuli placed on the contra forelimb,
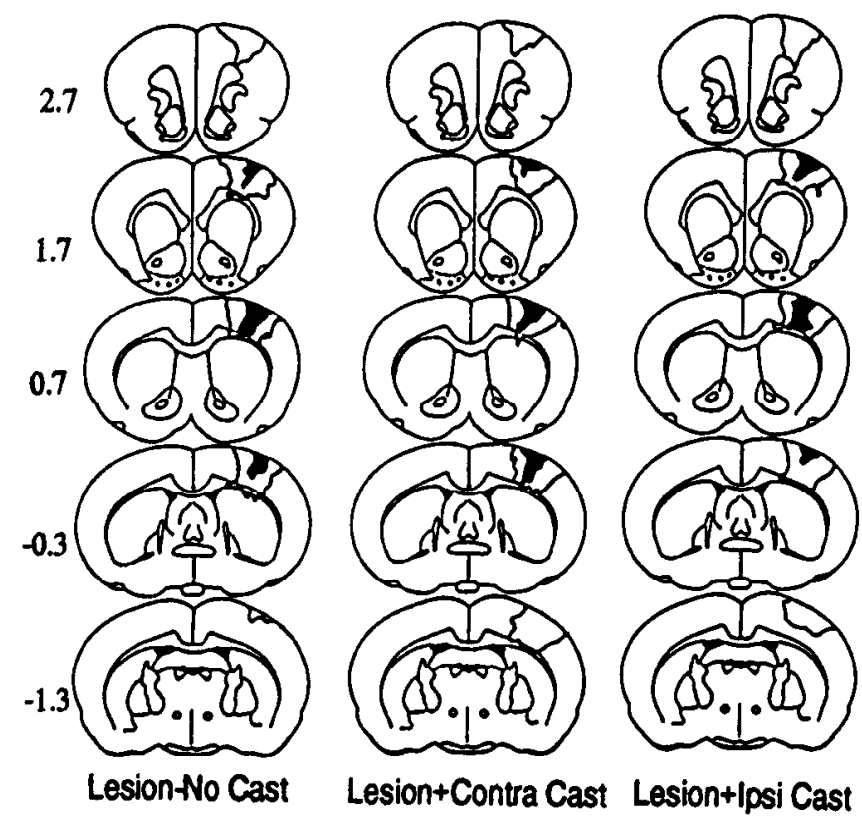

Figure 8. Representation of the area of common damage (black) and the outer border of all lesions (solid lines) in lesion groups used for delayed limb restriction (experiment 2).

but this was not significantly different from lesion-no cast. Casting one limb in sham animals did not significantly affect asymmetries or latency to respond to tactile stimuli.

\section{Experiment 2: delayed forelimb restriction}

Forcing animals to use only the ipsilateral forelimb between 20 and $35 \mathrm{~d}$ after the lesion failed to prevent the regression of dendritic arbors. As shown in Figure 8, lesion placement and extent were similar between groups and to lesions described in experiment 1 .

\section{Dendritic arborization}

Dendritic branching. The total number of dendritic branches per neuron for each of the lesion and sham groups is shown in Figure $9 A$. Immobilization of the impaired limb in SMC-X animals did not result in increased numbers of dendritic branches [i.e., did not prevent pruning; lesion + contra cast vs lesion-no cast, $F(1,48)=0.28, p>0.05]$, or the number of branches for any branch level ( $p \mathrm{~s}>0.05)$.

Lesion-no cast rats showed the greatest number of dendritic branches and this was significantly different from sham controls $[F(1,48)=4.40, p<0.05]$. Only modest increases were found at each second- and higher-order branch level. For example, lesion-no cast rats had $1.75 \pm 0.18$ fifth-order branches per neuron versus $1.40 \pm 0.10$ in sham-no cast. Only second-order branches were significantly different from sham $[F(1,48)=4.49$, $p<0.05$; mean $\pm \mathrm{SE}$ lesion-no cast: $4.72 \pm 0.09$, vs sham-no cast: $4.36 \pm 0.10$ ] although fourth- and fifth-order branches approached significance (e.g., fifth order, $F=3.31, p<0.08$ ). SMC-X animals with control casts showed similar means in comparison to SMC-X animals that had removed their casts (e.g., $20.92 \pm 0.87$ vs $21.09 \pm 0.91$ total branches, respectively). No significant effects were found between the lesion + ipsi cast group and the lesion-no cast group.

As in experiment 1, forced use of one forelimb in sham animals failed to increase significantly the number of basilar den- 
A

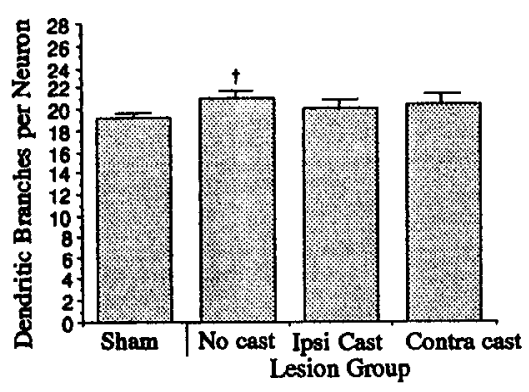

B

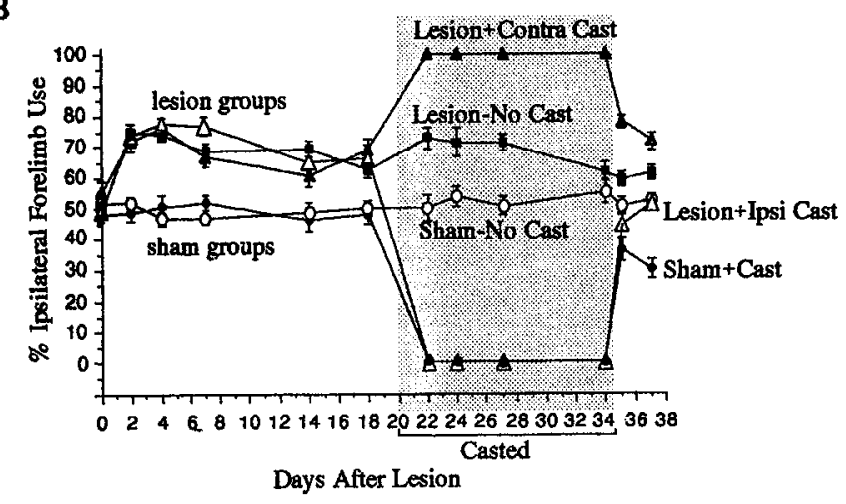

C

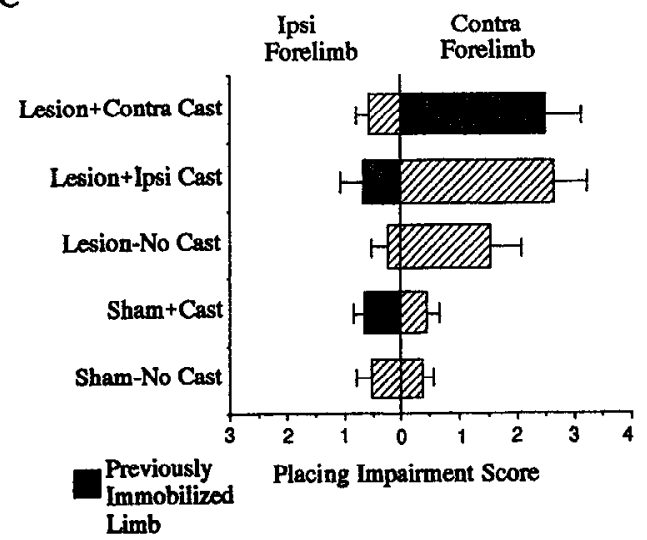

Figure 9. Results of delayed forelimb restriction. $A$, Basilar dendritic branch number. At $38 \mathrm{~d}$ after the lesion, Lesion-No Cast animals showed dendritic branch numbers that were only modestly increased relative to shams; that is, they were reduced in comparison to branch numbers found at $18 \mathrm{~d}$ postlesion (shown in Fig. 3). Forcing SMC-X animals to use the ipsilateral, nonimpaired limb between 20 and $35 \mathrm{~d}$ after the lesion failed to prevent a reduction in dendritic branch number. $\dagger, p<$ 0.05 significantly different from Sham-No Cast on planned comparisons. $B$, Asymmetry in the use of the forelimbs for postural-support behaviors. All SMC-X animals showed preferential use of the ipsilateral forelimb prior to casting. Following cast removal, the use of the previously casted limb was reduced in comparison to the lesion or sham control groups. $C$, Relative placing impairment on day 36. Unlike the effects of early restriction of the forelimb ipsilateral to the lesion, delayed casting did not significantly affect placing impairments.

dritic branches in the cortex opposite the forced-use forelimb. There were $19.38 \pm 0.85$ branches per neuron in the cortex opposite the forced-use limb versus $19.47 \pm 0.58$ opposite the immobilized limb and the number of branches per order was similar between hemispheres.

Concentric circle analysis. As with the dendritic branching, immobilization of the contra/impaired limb in SMC-X animals did not result in an increase in arborization as measured by circle intersections [lesion + contra cast vs lesion-no cast, group by circle interaction: $F(1,48)=1.61, p>0.05$ ]. The lesion + contra cast group had $44.11 \pm 1.58$ total intersections in comparison to $46.65 \pm 3.18$ in the lesion-no cast group.

Lesion-no cast intersections were only modestly increased relative to sham-no cast $(42.97 \pm 1.73)$. Lesion-no cast neurons showed the greatest number of circle intersections for the first eight circles, but intersections were significantly increased only at the first circle, or $20 \mu \mathrm{m}$ (mean \pm SE: lesion-no cast $=9.45$ \pm 0.35 , vs Sham-no cast $=8.61 \pm 0.20 ; p<0.05$, Tukey HSD). Group by circle analysis resulted in a significant effect for lesionno cast versus sham-no cast $[F(1,48)=9.63, p<0.002]$. No significant differences in arborization were found between lesion-no cast and lesion + ipsi cast.

No significant effects were found between hemispheres of sham + cast animals. The cortex opposite the forced-use limb had $39.74 \pm 2.70$ intersections per neuron in comparison to 41.51 \pm 2.10 opposite the immobilized forelimb.

\section{Forelimb use in postural support behaviors}

Limb-use asymmetry. Lesion-no cast animals showed preferential use of the ipsilateral forelimb throughout the days of observation (Fig. 9B). This was reduced after the fourth week postlesion, but remained significantly increased relative to shams [i.e., group by condition: precast, $F(1,190)=47.09, p<0.0001$; "casted," $F=37.37, p<0.0001$; postcast, $F=6.23, p<0.02]$. No significant effects were found between the lesion groups, or between the sham groups, prior to the limb immobilization procedure. SMC-X animals that removed their casts showed a similar asymmetry in comparison to SMC-X animals that were placed in two-holed, control casts (e.g., precast days, mean ipsilateral asymmetry $=69.57 \pm 2.04$ vs $68.41 \pm 1.78$, respectively).

After cast removal, animals showed limb-use asymmetries that shifted toward the mean values of lesion- and sham-no cast groups but were also reflective of their previously casted states, as in experiment 1 . Group by condition (postcast) analyses resulted in significant effects for sham + cast versus shamno cast $[F(1,190)=24.84, p<0.001]$, lesion + contra cast versus lesion-no cast $[F(1,190)=16.91, p<0.001]$, and lesion + ipsi cast versus lesion-no cast $[F(1,190)=10.65, p<0.002]$.

Forelimb activity. In contrast to the results of experiment 1 , the asymmetry in forelimb use appeared to be due to a combination of increased use of the ipsilateral forelimb as well as mild disuse of the contralateral forelimb in lesion-no cast rats (two-holed casts, omitting animals that had removed their casts; see Materials and Methods). However, the activity of neither forelimb of lesion-no cast rats was significantly changed relative to sham-no cast (e.g., precast, mean lesion-no cast activity $/ \mathrm{min}$ ipsi limb: $12.53 \pm 1.71$, contra limb: $5.98 \pm 0.92$, vs sham-no cast: $7.76 \pm 0.76$ and $8.48 \pm 0.83$, respectively; $p \mathrm{~s}>0.05$ ).

No significant effects were found hetween lesion groups prior to casting nor during casting for the nonimmobilized forelimb. Following cast removal, lesion + contra cast animals showed only $4.07 \pm 0.86$ instances of contralateral (previously casted) limb use per minute, which was reduced in comparison to 11.83 \pm 2.45 observations for lesion-no cast rats $[F(1,162)=7.08, p$ $<0.01]$. Lesion + ipsi cast rats showed no significant effects post-cast removal.

Consistent with the results from experiment 1 , the most fre- 
quently recorded precast behavior was activity at the wall. Following the casting procedure, all groups (including noncasted animals) showed a reduction in wall activity, but this effect was largest and most prolonged in lesion + ipsi cast animals. The proportion of activity at the wall in lesion + ipsi cast rats was $17.24 \pm 1.74$ during casting, which was reduccd in this group from $42.31 \pm 1.46$ prior to casting. Lesion + ipsi cast but not lesion + contra cast rats showed a significant reduction in proportional activity at the wall in comparison to lesion-no cast $[F(1,190)=17.78, p<0.001]$. Similar to the results of experiment 1 , following cast removal, the lesion + ipsi cast rats showed an ipsilateral (previously casted) bias for limb use at the wall, but not for other limb-use behaviors.

\section{Functional effects of delayed limb immobilization}

Placing impairment. Prior to casting, SMC-X animals showed mild but significant levels of contralateral placing impairment similar to those shown for lesion-no cast rats in experiment 1. Unlike the effects of early casts, delayed limb immobilization in lesion + ipsi cast rats did not result in a significantly increased placing impairment in comparison to lesion-no cast rats (Fig. $9 C$ ). Placing responses in lesion + contra cast and sham + cast rats were also not significantly affected by the casting procedure.

Response to somatic-sensory stimulation. In contrast to the results from experiment 1 , the lesion + ipsi cast group was not significantly different from lesion controls. Lesion-no cast animals showed little difference in the latency to contact ipsilaterally and contralaterally placed stimuli $(14.11 \pm 6.48$ vs $16.62 \pm$ 9.42 , respectively). However, lesion + contra cast rats showed greatly slowed responses to tactile stimulation applied to the contralateral (previously casted) forelimb $(9.08 \pm 1.35)$, which was significantly different from lesion-no cast $(p<0.05)$. There were no significant effects for any planned comparison of the tactile stimulation data obtained prior to casting.

\section{Discussion}

Unilateral lesions of the forelimb sensorimotor cortex of adult rats resulted in time-dependent changes in the dendritic morphology of layer $\mathrm{V}$ pyramidal neurons in the forelimb motor cortex of the opposite hemisphere. Pyramidal neuron dendritic arbors were extensively increased in complexity and size $18 \mathrm{~d}$ after the lesion. This increase corresponded to an over-reliance on the nonimpaired (ipsilateral to the lesion) forelimb in postural-motor behaviors. Preventing the use of the ipsilateral forelimb, but not the contralateral forelimb, during the first $15 \mathrm{~d}$ postlesion blocked the arborization changes.

Although these data link forelimb use and dendritic morphology, forelimb overuse per se was not sufficient to yield arborization increases. The presence of brain damage, perhaps specifically a lesion in the opposite cortex, appears to be necessary. Intact animals that were forced to use only one forelimb did not show significant increases in basilar dendritic arbors in the hemisphere opposite the overused forelimb relative to the hemisphere opposite the restricted limb. In addition, unilateral dopamine-depleting lesions of the nigrostriatal pathway have been found to cause a severe over-reliance on the ipsilateral forelimb (Schallert et al., 1992), but no significant interhemispheric differences were found in the complexity of layer $\mathrm{V}$ basilar dendritic branches of the forelimb motor cortex when examined at $18 \mathrm{~d}$ after the lesion (Jones, 1992). Unilateral pyramidal tract lesions cause scvere forelimb reaching asymmetries but no significant interhemispheric changes in layer $\mathrm{V}$ den-

A

EARLY CASTS First 15 days after the lesion

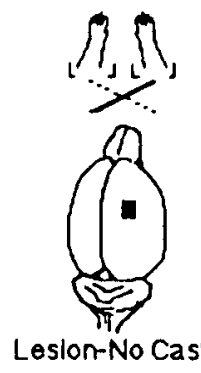

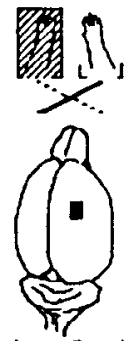

+ Contra Cast mpaired limb cast
DAY 18

increased dendritic arborization in cortex opposite the lesion

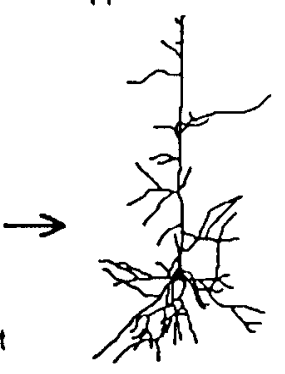

No significant change in arborization

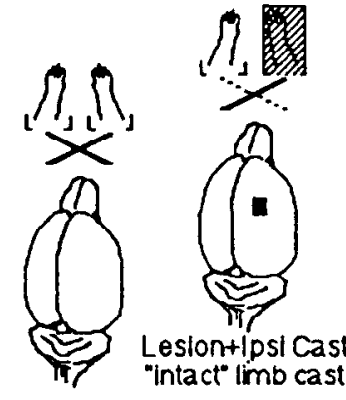

Sham-No Cast

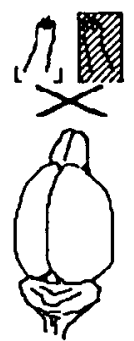

Snam+Cast

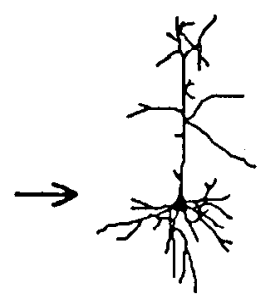

\section{B DELAYED CASTS 20 through 35 days after the lesion \\ DAY 38 \\ Pruning}

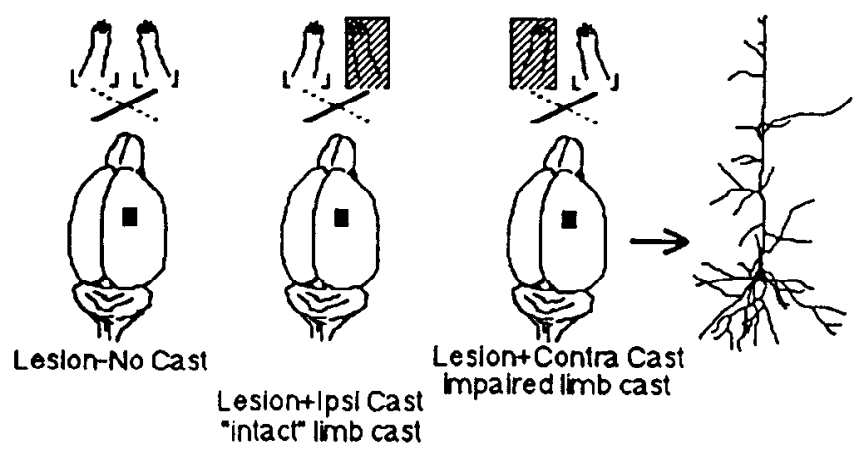

Figure 10. Summary of results. $A$, SMC-X animals with no limb immobilization or with the contralateral limb restricted (top) showed increased arborization at $18 \mathrm{~d}$ after the lesion. SMC-X animals that were prevented from using the forelimb opposite the arborization changes (Lesion + Ipsi Cast) showed normal levels of dendritic extent and complexity. Restriction of one forelimb in sham animals failed to affect branching in either hemisphere. $B$, All SMC-X animals regardless of casting condition showed a reduction in dendritic arbors at 38 days in comparison to day 18 postlesion. Hatching, forelimb restricted by the cast.

dritic arbors of the forelimb representation area (Whishaw et al., 1993). Thus, basilar dendritic arborization increases at 18 $\mathrm{d}$ were found only when there was both a lesion in the cortex of the opposite hemisphere and an over-reliance on the forelimb contralateral to the site of arborization. It therefore seems possible that a cortical lesion initiates a process that prepares the contralateral cortex for behaviorally mediated neural plasticity. 
One postlesion event that may influence the neural morphological change is terminal degeneration of transcallosal afferents originating from the lesion site. Extensive direct transcallosal connections are found in motor cortex, with densest callosal terminations in layers II and III and more modest terminations in layer $\mathrm{V}$, whereas callosal terminations in granular zones of the primary somatic-sensory cortex are sparse (Wise and Jones, 1976; Akers and Killackey, 1978; Donoghue and Parham, 1983; Koralek et al., 1990). Whether the overlapping somatic-sensory and motor representation region of the forelimb receives direct afferents from the contralateral homotopic cortex has not to our knowledge been specifically addressed. However, it is conceivable that even modest terminal degeneration within the area of measurement, in neighboring cortical areas and/or contralateral projection sites, could facilitate growth, for example, via increased production and release of tropic factors or other substances/substrates that might aid in reactive synaptogenesis. Although these possibilities are speculative, a lesion-induced increase in tropic support of these layer $V$ pyramidal neurons might then prime them for the effects of a lesion-induced behavioral demand. These issues would be more directly addressed by examining anatomical changes following transsections of the corpus callosum in rats showing forced or lesion-induced preferences for the use of one forelimb.

The failure to find increased basilar dendritic branching following forced use in sham-operated animals does not indicate that central structural changes failed to occur. It is possible that forced use affected a different population of neurons and/or the apical dendritic branches of layer $V$ ncurons. In intact animals, $16 \mathrm{~d}$ of reach training in one forelimb has been found to result in increases in the hasilar dendritic arbors of subpopulations of layer II/III pyramidal neurons (Withers and Greenough, 1989) and the apical dendritic branches of layer $V$ pyramidal neurons (Greenough et al., 1985) in the hemisphere contralateral to the trained limb. It is also possible that a more demanding or longer duration of forced use would have resulted in basilar dendritic arborization increases. Nevertheless, these findings indicate that forced use in intact animals does not reproduce the form of usedependent increases in dendritic branches found in SMC-X animals.

It has been suggested previously that increases in activity alone may not necessarily be sufficient to cause increases in synaptic connections of cortical neurons in intact animals, but that some learning process may also be required (Black et al., 1990; Grecnough and Anderson, 1991). For example, the learning of complex motor skills has been found to result in an increase in cerebellar Purkinje cell synapses whereas simple exercise did not lead to changes in synapse number (Black et al., 1990). The present studies do not dissociate clearly the effects of motor activity and motor learning, but there is some indication that postlesion activity of the ipsilateral forelimb is not solely responsible for the behaviorally linked dendritic effects. Unilateral lesions tended to cause both a decrease in contralateral limb use and an increase in ipsilateral limb use. However, changes in the activity of the ipsilateral limb were nonsignificant in comparison to sham animals. In experiment 1 , the asymmetry in forelimb use was due almost exclusively to a reduction in the activity of the contralateral forelimb. Furthermore, forelimb use in the postural-motor behaviors measured in the present experiments was found to be sensitive to practice effects. Limb immobilization in sham animals resulted in preferential use of the forced-use limb after cast removal. In addition, SMC-X animals that were forced to use only the contralateral forelimb showed contralateral limb preferences after cast removal for all behaviors that were expressed frequently during casting, but not for upright support against the walls of the cage or platform, a behavior that was reduced in frequency by the casting. Therefore, arborization increases were found in the absence of clear increases in ipsilateral limb activity and were related to use of the forelimbs in behaviors that appear to have a significant learning component. It is possible that the arborization changes are importantly dependent on a learned over-reliance on the ipsilateral forelimb to compensate for lesion-induced impairments of the contralateral forelimb.

An interesting question is whether, in addition to neuromorphological changes, postlesion forelimb asymmetries lead to changes in the extent of the forelimb representation area as determined using neurophysiological procedures. This might be expected based on extensive evidence of remodeling of cortical representational maps following neocortical lesions and behavioral or other peripheral manipulations (e.g., Jenkins and Merzenich, 1987; Pons et al., 1988, 1991; Doetsch et al., 1990; Jenkins et al., 1990; Kaas, 1991; Recanzone et al., 1992; see also Nudo et al., 1992). It is unknown how changes in cortical representational areas may be related to findings of experienceor lesion-induced synaptic and neural-morphological changes in the neocortex of adult animals (e.g., Greenough et al., 1985; Kolb and Gibb, 1991; Jones and Schallert, 1992a; see also DunnMeynell et al., 1992), although such anatomical changes might be expected to be reflected in representational maps. Furthermorc, it is conccivable that changes in pattcrns of ncural activity proposed to underlie cortical map remodeling (Allard et al., 1991; Jacobs and Donoghue, 1991) could, under certain, perhaps prolonged, conditions, lead to neuronal-structural and synaptic-connectional changes.

After the growth of dendritic arbors there was a partial reduction in complexity and size. That is, although dendritic arborization remained modestly increased relative to shams, the dendrites appeared to be "pruned" relative to pyramidal neurons examined earlier after the lesion. However, forcing animals to use only the ipsilateral forelimb throughout the period of pruning did not prevent the dendritic arbor reduction. Thus, the cause of the dendritic pruning and its behavioral significance remains elusive. One possibility that could not be addressed sufficiently using the methods of the present experiments is that compensatory ipsilateral limb use, in addition to its role in arbor enlargement, also causes arbor pruning. Arbor reductions were not prevented by either ipsilateral or contralateral forelimb restriction during the expected pruning period, but it remains possible that the dendritic regression takes qualitatively different forms in the two cases. That is, dendritic elimination may occur with restriction of the unimpaired ipsilateral limb due to a sensorimotor deprivation effect and a qualitatively different form of "pruning" due to required or permitted use of the ipsilateral limb. The former could be a degenerative effect of a net reduction/asynchrony in activity of synapses (see Hubel and Wiesel, 1965; Lo and Poo, 1991; Purves et al., 1992), whereas the latter might be a result of competition between active synapses and selective maintenance of some synaptic connections, as suggested in nervous system development (Changeux and Danchin, 1976; Greenough and Chang, 1988; Purves et al., 1988). Reductions in the size of dendritic arbors are not necessarily associated with a net reduction in the number of synaptic connections but are associated with increased specificity of afferent 
input. In autonomic ganglia, dendritic arbor size and complexity are proportional to the number of different innervating axons (Purves and Hume, 1981; Purves and Lichtman, 1985). On the other hand, dendritic arbor size is also reduced following deafferentation or blockade of the activity of afferent input (Born and Rubel, 1988; Deitch and Rubcl, 1989) or blockade of target activity (Sumner and Watson, 1971; Purves et al., 1988). Thus, arbors may be reduced in the presence of either increased specificity of synaptic input or decreased afferent/target activity.

The compensatory use of the ipsilateral forelimb and the associated arborization changes in the nondamaged cortex were related to improved function following the unilateral lesions. Restricting the use of the ipsilateral forelimb in the first $15 \mathrm{~d}$ postlesion not only blocked the arborization changes but also caused a mild but generalized decrement in bilateral performance on tests of sensorimotor function. This effect was time dependent. Restriction of the ipsilateral forelimb for the same duration after animals had been allowed to use it preferentially for $20 \mathrm{~d}$ did not affect significantly the sensorimotor test measures. In contrast, immobilization of the contralateral forclimb early after the lesion failed to affect bilateral sensorimotor function significantly in comparison to SMC-X animals that were allowed to use both forelimbs. These findings may be of relevance to human studies of hemiplegia in which the use of the intact arm is restricted in attempts to improve function of the affected arm (Ostendorff and Wolf, 1981; Wolf et al., 1989). The present results suggest that such an approach to improving the function of the affected limb may be accomplished in certain circumstances, perhaps particularly immediately after the brain damage, only at the expense of worsened overall function. Because the compensatory use of the ipsilateral limb is related to improved function and to the time-dependent dendritic branching, there may exist a postlesion time period during which the development of compensatory strategies involving the use of the nonimpaired limb is optimal.

\section{References}

Akers RM, Killackey HP (1978) Organization of corticocortical connections in the parietal cortex of the rat. J Comp Neurol 181:513538.

Allard T, Clark SA, Jenkins WM, Merzenich MM (1991) Reorganization of somatosensory area $3 \mathrm{~b}$ representations in adult owl monkeys after digital syndactyly. J Neurophysiol 66:1048-1058.

Barth TM (1986) Sensorimotor function of the rat neocortex. PhD thesis, University of Texas, Austin.

Barth TM, Schallert T (1987) The role of the superior colliculus, somatosensory cortex and lateral hypothalamus in somatosensory function in the rat. Exp Neurol 95:661-678.

Barth TM, Jones TA, Schallert T (1990) Functional subdivisions of the rat somatic sensorimotor cortex. Behav Brain Res 39:73-95.

Black JE, Isaacs KR, Anderson BJ, Alcantara AA, Greenough WT (1990) Learning causes synaptogensis, whereas motor activity causes angiogenesis, in cerebellar cortex of adult rats. Proc Natl Acad Sci USA 87:5568-5572.

Bom DE, Rubel EW (1988) Afferent influences on brain stem auditory nuclei of the chicken: presynaptic action potentials regulate protein synthesis in nucleus magnocellularis neurons. J Neurosci 8:901-919.

Castro AJ (1977) Limb preferences after lesions of the cerebral hemisphere in adult and neonatal rats. Physiol Behav 18:605-608.

Changeux J-P, Danchin A (1976) Selective stabilisation of developing synapses as a mechanism for the specification of neuronal networks. Nature 264:705-712.

Coleman PD, Riesen AH (1968) Environmental effects on cortical dendritic fields. I. Rearing in the dark. J Anat 102:363-374.

Colle LM, Holmes LJ, Pappius HM (1986) Correlation between be- havioral status and cerebral glucose utilization in rats following freezing lesion. Brain Res 37:263-268.

Deitch JS, Rubel EW (1989) Rapid changes in ultrastructure during deafferentation-induced dendritic atrophy. J Comp Neurol 281:234258.

De Ryck M, Van Reempts J, Duytschaever H, Van Deuren B, Clincke $G$ (1992) Neocortical localization of tactile/proprioceptive limb placing reactions in the rat. Brain Res 573:44-60.

Doetsch GS, Johnston KW, Hannan CJ (1990) Physiological changes in the somatosensory forepaw cerebral cortex of adult raccoons following lesions of a single cortical digit representation. Exp Neurol 108:162-175.

Donoghue JP, Parham C (1983) Afferent connections of the lateral agranular field of the rat motor cortex. J Comp Neurol 217:390-404.

Donoghue JP, Wise SP (1982) The motor cortex of the rat: cytoarchitecture and microstimulation mapping. J Comp Neurol 212:7688.

Donoghue JP, Suner S, Sanes JN (1990) Dynamic organization of primary motor cortex output to target muscles in adult rats. II. rapid reorganization following motor nerve lesions. Exp Brain Res 79:492503.

Dunn-Meynell, AA, Benowitz LI, Levin BE (1992) Vibrissectomy induced changes in GAP. 43 immunoreactivity in the adult rat barrel cortex. J Comp Ncurol 315:160-170.

Faugier-Grimaud S, Frenois C, Stein DG (1978) Effects of posterior parietal lesions on visually guided behavior in monkeys. Neuropsychologia 16:151-168.

Flood DG, Buell SJ, Horwitz GJ, Coleman PD (1987) Dendritic extent in human dentate gyrus granule cells in normal aging and senile dementia. Brain Res 402:205-216.

Greenough WT, Anderson BJ (1991) Cerebellar synaptic plasticity, relation to learning versus neural activity. Ann NY Acad Sci 627: 231-247.

Greenough WT, Chang F-LF (1988) Dendritic pattern formation involves both oriented regression and oriented growth in the barrels of mouse somatosensory cortex. Dev Brain Res 43:148-152.

Greenough WT, Larson JR, Withers GS (1985) Effects of unilateral and bilateral training in a reaching task on dendritic branching of neurons in the rat motor-sensory forelimb cortex. Behav Neural Biol 44:301-314.

Hall RD, Lindholm EP (1974) Organization of motor and somatosensory neocortex in the albino rat. Brain Res 66:23-38.

Hubel DH, Wiesel TN (1965) Binocular interaction in striate cortex of kittens reared with artificial squint. J Neurophysiol 28:1041-1059.

Jacobs KM, Donoghue JP (1991) Reshaping the cortical motor map by unmasking latent intracortical connections. Science 251:944-947.

Jenkins WM, Merzenich MM (1987) Reorganization of neocortical representations after brain injury: a neurophysiological model of the bases of recovery from stroke. Prog Brain Res 71:249-266.

Jenkins WM, Merzenich MM, Ochs MT, Allard T, Guic-Robles E (1990) Functional reorganization of primary somatosensory cortex in adult owl monkeys after behaviorally controlled tactile stimulation. J Neurophysiol 63:82-104.

Jones TA (1992) Dendritic overgrowth and pruning of pyramidal neurons after neocortical damage: relation to behavior. $\mathrm{PhD}$ thesis, University of Texas, Austin.

Jones IA, Schallert T (1989) Sensorimotor cortex lesions: time-dependent anatomical changes specific to the contralateral homotopic cortex. Soc Neurosci Abstr 15:1223.

Jones TA, Schallert T (1992a) Overgrowth and pruning of dendrites in adult rats recovering from ncocortical damage. Brain Res 581:156160.

Jones TA, Schallert T (1992b) Subcortical deterioration after cortical damage: effects of diazepam and relation to recovery of function. Behav Brain Res 51:1-13.

Kaas JH (1991) Plasticity of sensory and motor maps in adult mammals. Annu Rev Neurosci 14:137-167.

Kolb B, Gibb R (1991) Environmental enrichment and cortical injury: behavioral and anatomical consequences of frontal cortex lesions. Cereb Cortex 1:189-198.

Kolb B, Whishaw IQ (1989) Plasticity in the neocortex: mechanisms underlying recovery from early brain damage. Prog Neurobiol 32: 235-276.

Koralek K-A, Olavarria J, Killackey HP (1990) Areal and laminar 
organization of corticocortical projections in the rat somatosensory cortex. J Comp Neurol 299:133-150.

Lo Y-J, Poo M-M (1991) Activity-dependent synaptic competition in vitro: heterosynaptic suppression of developing synapses. Science 254 : 1019-1022.

Neafsey EJ, Bold EL, Haas G, Hurley-Guis KM, Quirk G, Sievert CF, Terreberry RR (1986) The organization of the rat motor cortex: a microstimulation mapping study. Brain Res Rev 11:77-96.

Nudo RJ, Jenkins WM, Merzenich MM, Prejean T, Grenda R (1992) Neurophysiological correlates of hand preference in primary motor cortex of adult squirrel monkeys. J Neurosci 12:2918-2947.

Ostendorff CG, Wolf SL (1981) Effect of forced use of the upper extremity of a hemiplegic patient on changes in function. Phys Ther 61:1022-1028.

Passingham RE, Perry VH, Wilkinson F (1983) The long-term effects of removal of sensorimotor cortex in infant and adult rhesus monkeys. Brain 106:675-705.

Paxinos G, Watson C (1986) The rat brain in stereotaxic coordinates, 2d ed. Sydney: Academic.

Peterson GM, Francarol C (1938) The relative influence of the locus and mass of destruction upon the control of handedness by the cerebral cortex. J Comp Neurol 68:173-190.

Pons TP, Garraghty PE, Mishkin M (1988) Lesion-induced plasticity in the second somatosensory cortex of adult macaques. Proc Natl Acad Sci USA 85:5279-5281.

Pons TP, Garraghty PE, Ommaya AK, Kaas JH, Taub E, Mishkin M (1991) Massive cortical reorganization after sensory deafferentation in adult macaques. Science 252:1857-1860.

Purves D, Hume RI (1981) The relation of postsynaptic geometry to the number of presynaptic axons that innervate autonomic ganglion cells. J Neurosci 1:441-452.

Purves D, Lichtman JW (1985) Geometrical differences among homologous neurons in mammals. Science 228:298-302.

Purves D, Snider WD, Voyvodic JT (1988) Trophic regulation of nerve cell morphology and innervation in the autonomic nervous system. Nature 336:123-128.

Purves D, Riddle DR, LaMantia A-S (1992) Iterated patterns of brain circuitry (or how the cortex gets its spots). Trends Neurosci 15:362 368.

Recanzone GH, Merzenich MM, Jenkins WM, Grajski KA, Dinse HR (1992) Topographic reorganization of the hand representation in cortical area $3 \mathrm{~b}$ of owl monkeys trained in a frequency-discrimination task. J Neurophysiol 67:1031-1056.
Schallert T, Whishaw IQ (1984) Bilateral cutaneous stimulation of the somatosensory system in hemi-decorticate rats. Behav Neurosci 98: $518-540$.

Schallert T, Upchurch M, Wilcox RE, Vaughn DM (1983) Posture independent sensorimotor analysis of inter-hemispheric receptor asymmetries in the neostriatum. Pharmacol Biochem Behav 18:753759

Schallert T, Hernandez TD, Barth TM (1986) Recovery of function after brain damage: severe and chronic disruption by diazepam. Brain Res 379:104-111.

Schallert T, Norton D, Jones TA (1992) A clinically relevant unilateral model of parkinsonian akinesia. J Neurotransplant Plast 3:332-333.

Sholl DA (1956) The organization of the cerebral cortex. London: Methuen.

Sumner BEH, Watson WE (1971) Retraction and expansion of the dendritic tree of motor neurones of adult rats in vivo. Nature 223 273-275

Uylings HBM, Van Pelt J, Verwer RWH (1989) Topological analysis of individual neurons. In: Computer techniques in neuroanatomy (Capowski JJ, ed), pp 215-238. New York: Plenum.

Whishaw IQ, O'Conner WT, Dunnett ST (1986) The contributions of motor cortex, nigrostriatal dopamine and caudate-putamen to skilled forelimb use in the rat. Brain 109:805-843.

Whishaw IQ, Pellis SM, Gorny BP, Pellis VC (1991) The impairments in reaching and the movements of compensation in rats with motor cortex lesions: an endpoint, videorecording, and movement notation analysis. Behav Brain Res 42:77-91.

Whishaw IQ, Pellis SM, Gorny B, Kolb B, Tetzlaff W (1993) Proximal and distal impairments in rat forelimb use in reaching follow unilateral pyramidal tract lesions. Behav Brain Res 56:59-76.

Wise SP, Donoghue JP (1986) Motor cortex of rodents. In: Cerebral cortex, Vol 5 (Jones EG, Peters A, eds), pp 243-270. New York: Plenum.

Wise SP, Jones EG (1976) The organizational and post-natal development of the commissural projection of the rat somatic sensory cortex. J Comp Neurol 168:313-344.

Withers GS, Greenough WT (1989) Reach training selectively alters dendritic branching in subpopulations of layer II-III pyramidals in rat motor-somatosensory forelimb cortex. Neuropsychologia 27:6169.

Wolf SL, Lecraw DE, Barton LA, Jann BB (1989) Forced use of hemiplegic upper extremity to reverse the effect of learned nonuse among chronic stroke and head injured patients. Exp Neurol 104:125-132. 